\title{
GRID: Una xarxa europea per a la bona pràctica en l'ensenyament de les ciències
}

\author{
Sibylle Moebius
}

smoebius@amitie.it

Presentació del projecte GRID, per a identificar i promoure la innovació en l'educació de les ciències a Europa.

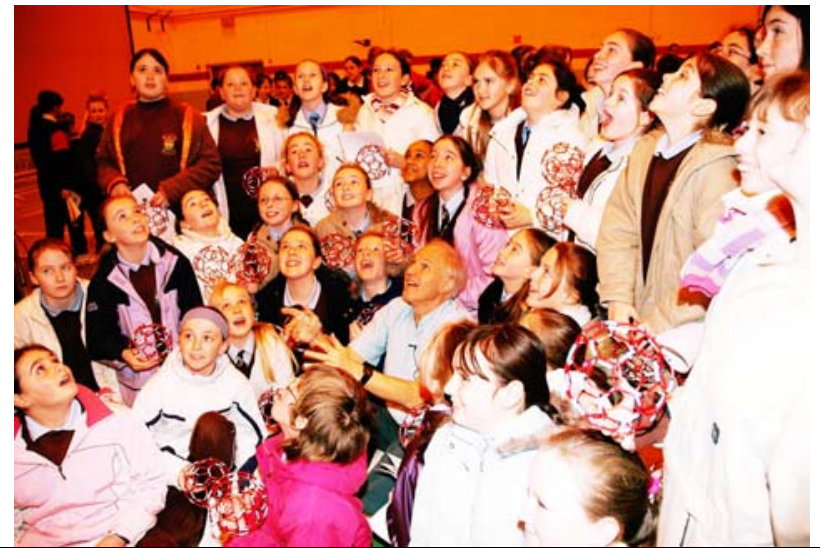

El senyor Harry Kroto en un taller per a alumnes de primària a Waterford, Irlanda.

El projecte GRID (GRowing Interest in the Development of teaching science) té el propòsit de crear una xarxa de dinamitzadors i escoles per a l'intercanvi de bones pràctiques en l'ensenyament de ciències a nivell europeu. L'objectiu principal és identificar, analitzar i promoure iniciatives per fer l'ensenyament de les ciències més atractiu tan a primària com a secundària. El propòsit final és divulgar, via web (1), les millors pràctiques identificades.

La primera fase del projecte GRID ha consistit en analitzar l'impacte directe de la política educativa europea a les escoles. Això s'ha fet revisant informes, suggeriments i projectes institucionals publicats per ministeris, autoritats regionals i locals, i institucions educatives. Actualment s'està acabant de preparar aquest informe, que estarà disponible a la pàgina web del GRID.

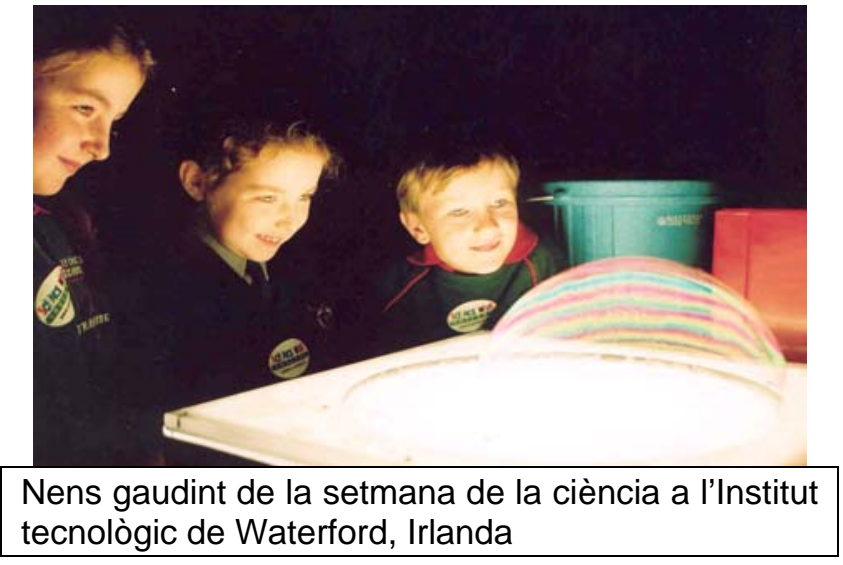

A través de la pàgina web del GRID s'ha iniciat una enquesta per tal d'identificar i analitzar l'existència d'iniciatives escolars que incrementin l'atractiu de les ciències. Si ets un professor de ciències a primària o secundària, tant si estàs involucrat en una iniciativa aïllada de classe com si gestiones un projecte local, estatal, nacional o fins i tot internacional, t'animem a participar-hi.

Per a cada país participant es seleccionaran els millors projectes com a casos d'estudi (mínim 6, màxim 12). L'objectiu dels casos d'estudi és maximitzar l'impacte dels projectes existents i fomentarne la difusió a nivell europeu. Els casos d'estudi poden incloure vídeos i entrevistes dels professors involucrats.

Posteriorment, els tallers s'organitzaran a cada país participant, on els professors podran compartir les seves experiències i aconsellar-ne d'altres interessats a muntar projectes científics educatius similars. 


\section{Els primers resultats}

L'estudi europeu d'innovació en l'ensenyament de les ciències, GRID, ja ha identificat alguns projectes interessants.

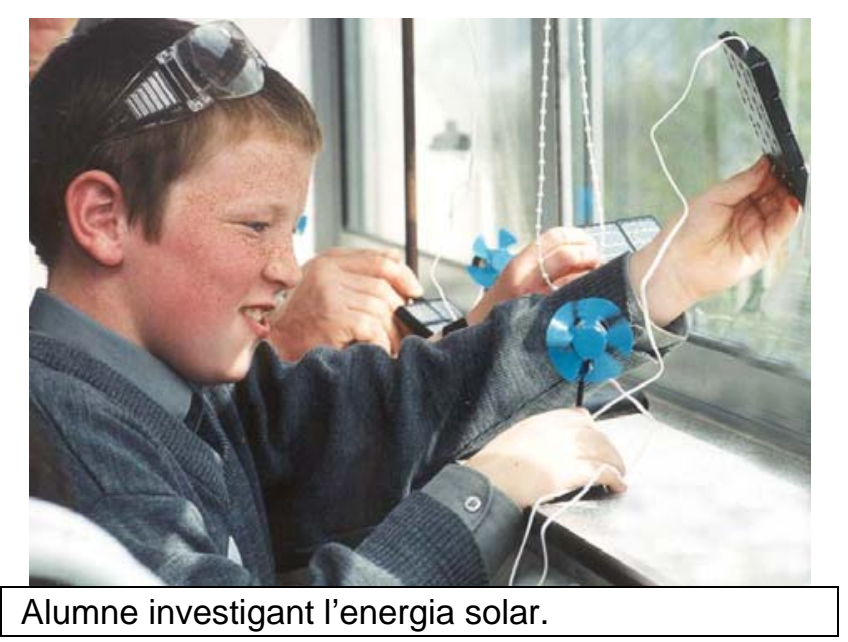

\section{La física és guai, Bèlgica (Physics is Cool)}

La Universitat d'Anvers ha desenvolupat un projecte per secundaria anomenat "La física és guai" (2). En uns 40 kits hi ha tot el material necessari per dur a la pràctica una amplia gama d'experiments amb alumnes de 14 a 17 anys. També hi estan inclosos una guia pel professorat $i$ un CD. Els experiments pretenen provocar discussió i millorar la comunicació científica entre estudiants, fer-los adonar de les causes dels fenòmens quotidians, i confrontar-los amb experiments que són força fàcils de fer però difícils d'explicar.

\section{El projecte d'Ada Lovelace: la mentora per dones en ciències i tecnologia, Alemanya (The Ada Lovelave Project: mentoring for women in science and technology)}

Les estudiants universitàries de ciències, enginyeries i matemàtiques actuen com a mentores en escoles femenines dins del projecte Ada Lovelace (3).

Amb la supervisió de pedagogs i psicòlegs les mentores han après mètodes de comunicació i moderació. Visiten escoles i parlen sobre les raons d'estudiar ciències, enginyeria o matemàtiques, donen consells per superar obstacles i informen a les estudiants sobre la vida universitària. En segon terme les mentores inviten les noies a participar en cursos universitaris i treballs de laboratori.

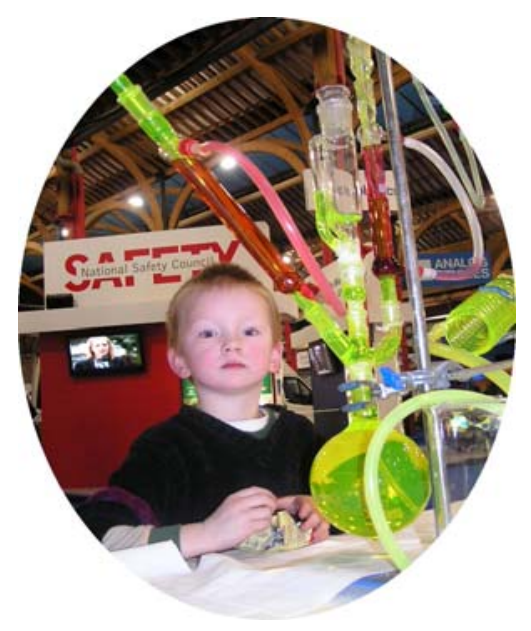

Nen participant a l'estand de química, CALMAST, en l'exposició de joves científics i tecnòlegs, Irlanda

\section{Centre per a l'aprenentatge de la vida (Life Learning Center), Itàlia}

L'objectiu principal del Life Learning Center (4) és proporcionar pràctiques de laboratori sobre les ciències de la vida als mestres i alumnes, a la Universitat. Aprenen sobre biologia molecular, genètica i biotecnologia, i utilitzen equipament de laboratori innovador amb el suport i supervisió de tutors universitaris.

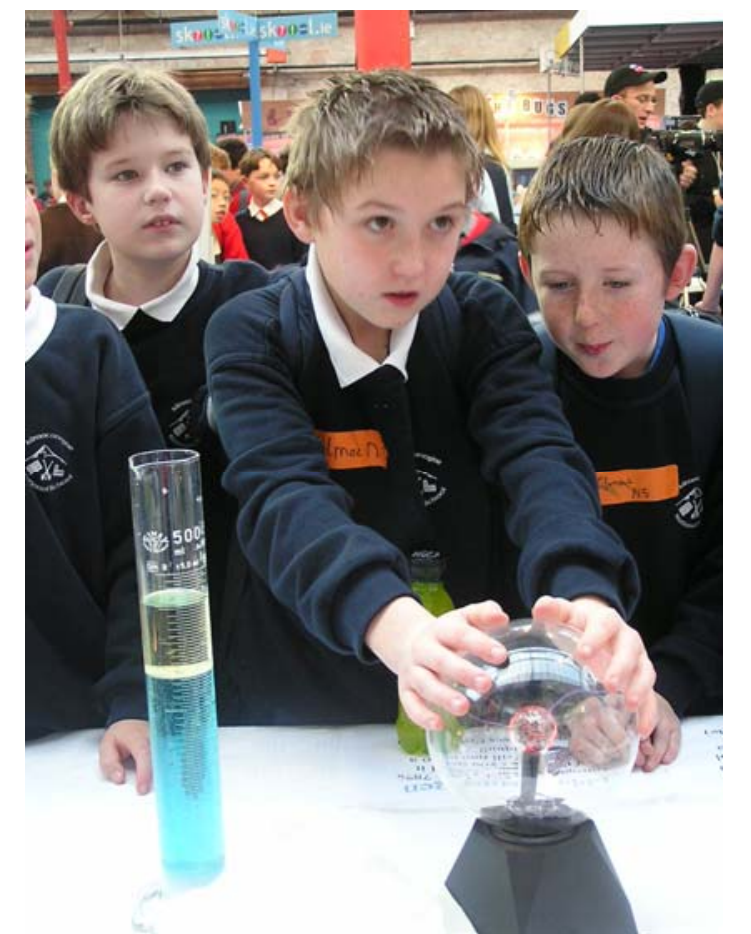

Alumnes de primària a l'exposició de joves científics, Irlanda. 


\section{Química a la feina, Gran Bretanya (Chemistry at Work)}

"Química a la feina" (5) vol demostrar als estudiants la importància de la química en la nostra vida $i$ feina de cada dia, donant una èmfasi especial en allò que passa al seu entorn. Les pràctiques ofereixen una imatge positiva de la química i la presenten amb activitats emocionants, interessants i econòmicament profitoses, que val la pena considerarles com a base de la carrera.

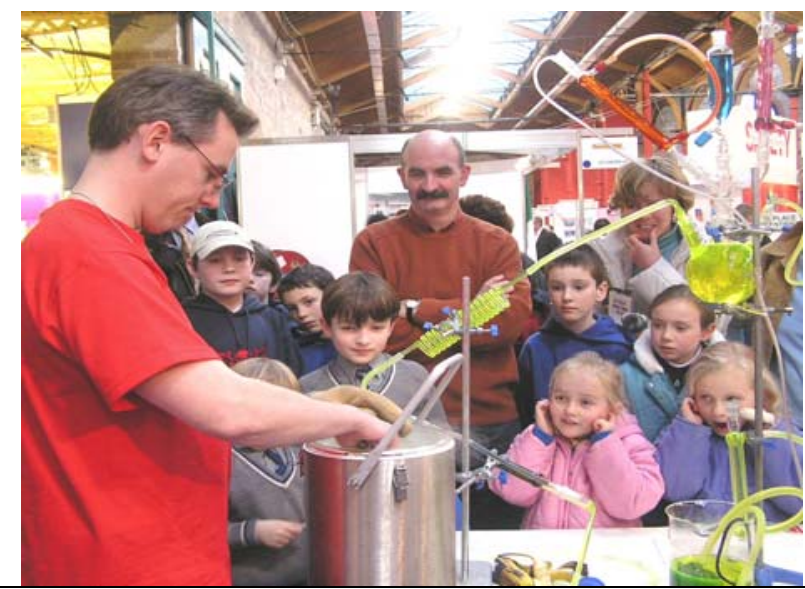

Eoin Gill a l'estand del CALMAST a l'exposició de joves científics, Irlanda.

\section{Actualitzacions del projecte GRID}

El butlletí de notícies del GRID, disponible a la pàgina web o per e-mail, està dirigit als projectes participants, als professors de ciències, als dinamitzadors, col-laboradors $i$ tots aquells involucrats $i$ interessats en els projectes. Informa sobre els diferents projectes, les seves activitats i esdeveniments, i proporciona informació pràctica als participants i col.laboradors.

Per a subscriure's aquest butlletí gratuït, envia un e-mail a Sibylle Moebius (smoebius@amitie.it) amb el teu nom, cognoms, professió, país i l'adreça de correu electrònic.

\section{Agraïments}

El projecte GRID ha estat finançat dins del marc del Programa Sòcrates de la Unió Europea, coordinat per la universitat Pôle Universitaire Européen de Nancy-Metz, França, i realitzat pel consorci multidisciplinari Europeu.

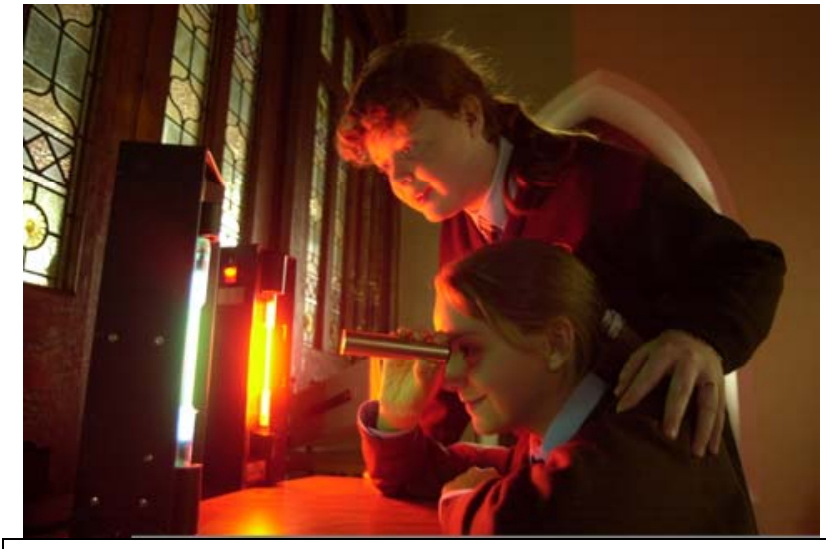

Laboratori de I'Institut tecnològic de Waterford, Irlanda

\section{Referències}

(1) Pàgina web del GRID

http://www.grid-network.eul

(2) La física és guai

http://webhost.ua.ac.be/focus/Koffers/english.htm

(3) El projecte d'Ada Lovelace

http://www.uni-koblenz.de/ alp/projekt en.htm

(4) Life Learning Center

http://www.golinellifondazione.org/eng/

(5) Química a la feina

http://www.rsc.org/Education/chemwork/

Les imatges d'aquest article són una gentilesa de la participant en la xarxa GRID Sheila Donegan, CALMAST, Waterford Institute of Technology, Irlanda.

Aquest article va aparèixer en el número 2 de la revista europea 'Science in School', adreçada a estimular l'ensenyament de les ciències:

www.scienceinschool.org

Informació sobre copyright:

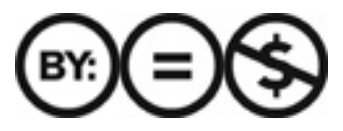

Traducció: Gemma Bernabeu 